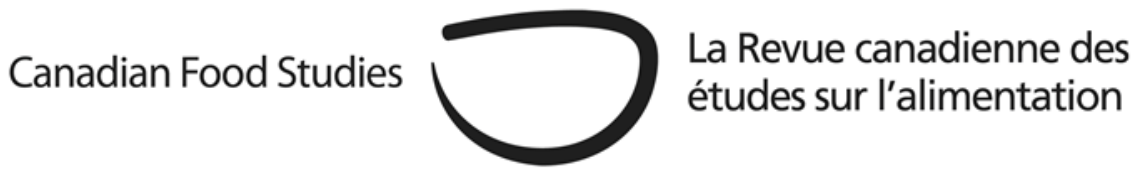

Original Research Article

\title{
Examining local food procurement: Adaptive capacities and resilience to environmental change in Fort Providence, Northwest Territories
}

Paulina Paige Ross* and Courtney W Mason

Thompson Rivers University

\begin{abstract}
By exploring localized adaptation strategies for climate change, this paper aims to provide a deeper understanding of local perspectives and efforts regarding food procurement in Fort Providence, Northwest Territories (NT). The benefits and risks associated with engaging in local food procurement activities are key topics explored. Strategies to manage food insecurity and local approaches to encourage food procurement are also considered. This study was informed by Indigenous methodologies, which guided all aspects of this research. While the researchers have collaborated with community members since 2010, evidence for this study was collected during two field seasons in the spring and fall of 2018, using semi-structured interviews with Elders, land-users, and knowledgeable community members. Findings support decentralized policy developments which focus on the integration of local voices into decision-making processes and program implementation. Food policies must reflect the needs of residents at localized levels and the distinct socio-cultural and economic barriers to procuring food, and they must encourage overall community resilience and adaptive capacities to climate-related change. This research supports regional and national efforts to reduce food insecurity across northern Canada by documenting traditional knowledge concerning climate change and local food practices in Fort Providence.
\end{abstract}

Keywords: Food security; climate change; Indigenous peoples; rural; subarctic

*Corresponding author: paulinaross10@gmail.com 


\section{Introduction}

Food security ${ }^{1}$ challenges among Indigenous communities in northern Canada are a significant concern that is exacerbated by changing socio-cultural, economic, and environmental conditions (Council of Canadian Academies, 2014; Kenny et al., 2018; Rosol et al., 2016; Skinner et al., 2013; Spring et al., 2018). The Northwest Territories (NT) report that $19.3 \%$ of adults over the age of 12 are food insecure, while the national average is $7.3 \%$ (Northwest Territories [NT] Bureau of Statistics, 2014). Indigenous communities in the NT continue to rely on the environment for subsistence, and it supports, to a degree, food security and cultural resiliencies. The high level of food insecurity in the NT correlates with socio-cultural and economic barriers experienced disproportionately by Indigenous households, and this is aggravated by ongoing climate change (Council of Canadian Academies, 2014). Communities are coping with climatic change that is widely predicted to impact temperatures, weather patterns, sea levels, and ecosystems (Intergovernmental Panel on Climate Change [IPCC], 2014).

This paper aims to provide an understanding of local perspectives regarding communitywide resilience to climate change, while identifying current adaptive capacities to support local food procurement and improve food security in Fort Providence, NT. For the purposes of this paper, local food procurement is divided into two categories: wild foods and locally grown foods. Wild foods are resources harvested, hunted, fished, trapped, or foraged regionally from the land. ${ }^{2}$ Locally grown foods include vegetables and fruits produced in greenhouses, community gardens, or in aquaponic systems. Research indicates that community gardens and greenhouses are emerging in many northern communities as viable solutions to the limited availability of nutritious market foods and climate change-related barriers to land-based practices (Thompson et al., 2018; Chen \& Natcher, 2019). Consequently, this study considers these practices as adaptation strategies.

We contend in this paper that local adaptation strategies to shifting environmental conditions can aid northern food security initiatives, build resilience to climate related change, and support cultural continuities. In order to understand how a community can adapt food procurement practices to climate-related changes and socio-economic constraints, it is first imperative to understand where community vulnerabilities lie. These vulnerabilities are determined by the resources on which residents depend and also by the availability, access, quality, and stability of those resources (Adger et al., 2003). Community vulnerability to climate change can be conceptualized as a function of exposure-sensitivity to shifting environmental risks and the adaptive capacity to deal with those risks (Ford et al., 2006). Exposure-sensitivities reflect the susceptibility of people and communities to biophysical conditions that represent risk,

\footnotetext{
${ }^{1}$ Food security exists when all people, at all times, have physical, socio-cultural, and economic access to sufficient and nutritious food to meet dietary needs (Food and Agriculture Organization [FAO], 2017).

${ }^{2}$ For Fort Providence residents, this includes: many diverse species of fish; small game such as rabbits, geese, ducks, and beavers; big game such as moose, woodland caribou, or wood bison; and numerous plant and herb species (Wesche et al., 2016).
} 
while adaptive capacity refers to a community's potential to address, plan for, or adapt to exposure-sensitivities (Ford et al., 2010). Adaptation research is typically framed around a community risk assessment, which gathers data about livelihoods, resilience, and hazards (Aalst et al., 2008). This research did not focus on formalized risk assessments; instead, it centered on identifying local food procurement initiatives and recognizing their importance to support overall community resilience and adaptive capacity. The following questions are explored: 1) What are the benefits and risks of engaging in local food procurement?; 2) Do local food procurement strategies support adaptive capacity for climate change?; and 3) What are the barriers to engaging in local food procurement and adaptive capacities at local and regional levels?

\section{Community profile}

Fort Providence is a small Dene-Métis community located in the Deh Cho region of southern NT with approximately 800 residents (NT Bureau of Statistics, 2016). It is situated along the banks of the Mackenzie River, downstream from Great Slave Lake (Appendix A). The community is surrounded by several bodies of water that provide access to wild foods year-round. A freshwater delta positioned close to the community, where the Mackenzie River widens at the mouth of the Horn River, forms Mills Lake. The Horn River drains from the Horn Plateau, a region that has been a spiritual home for the Dene people, and an important harvesting location, for millennia. Besides hosting plentiful aquatic and semi-aquatic species, the plateau is a major staging area for waterfowl during spring and fall migrations, a refuge for molting diving ducks in the summer, a grazing area for wood bison in the winter, and a vital moose habitat year-round (ESTR Secretariat, 2013; Species at Risk Act, 2018).

Due to the plateau's significance to local peoples as a critical food harvesting location and their desire to conserve it for future generations, on October $11^{\text {th }}, 2018$, the Deh Cho First Nations Assembly designated Edéhzhíe as the first Indigenous Protected Area in Canada. ${ }^{3}$ Covering 14, 218 square kilometers, Edéhzhíe is ecologically important to the Deh Cho Dene culture, language, and ways of life (Deh Cho Government, 2018).

Fort Providence has a variety of services, including a local hotel, two small grocery stores and restaurants, a health center, a multipurpose sports center, and a territorial campground. One of the newest infrastructure developments in the region is the Deh Cho Bridge, which was

\footnotetext{
${ }^{3}$ The 2018 Federal Budget contained support for a $\$ 1$ billion nature fund. A new designation of park was endorsed, Indigenous Protected Areas (IPAs), which are designed and managed by Indigenous communities. IPAs will make a contribution to Canada's international commitment to protecting $17 \%$ of land and fresh water by 2020 . They will also support Indigenous capacity to conserve land and threatened species. By forming Edéhzhíe as an IPA, the management board will make its decisions by consensus while encouraging an Indigenous presence on the land. As local communities encounter even more barriers to food security, such as climate change and mounting food production and shipping costs, it is a crucial time to protect these lands from further development by establishing an IPA (Mason, 2018).
} 
completed in 2012. It is the only bridge across the Mackenzie River and the longest bridge in northern Canada (Government of the Northwest Territories [GNWT], 2018). As a consequence of this development, Fort Providence is one of few communities in the NT with all-weather road access.

While many Fort Providence residents maintain traditional practices and continue to be supported by wild foods, market foods make up the majority of foods consumed. However, growing food locally is slowly beginning to emerge as a key part of the local foods system. It is important to emphasize that wild foods and land-based practices remain important for the sociocultural roles they play in the community. Despite the abundance of natural resources in the area, community members must reply upon income support or employment opportunities to supplement livelihoods. Over half of the adult population in Fort Providence relies on paid income for full year, full time positions (NT Bureau of Statistics, 2016).

\section{Food security and climate change impacts on northern Canada}

The Food and Agricultural Organization (FAO) of the United Nations (2017) identifies four food security pillars: availability, access, utilization, and stability. Physical and socio-economic access to healthy, nutritious food that meets dietary and cultural needs varies between communities across Canada's North. Food availability relates to supply levels of food (FAO, 2017). This can include a community member's economic capabilities to purchase food available from the store, or it can refer to, for example, the availability and abundance of certain fish species. Food utilization is understood as the metabolism of food. In Fort Providence, this means preparing and processing culturally appropriate foods, or it can mean knowing how to cook vegetables from a local garden, such as harvested kale or Swiss chard. Wild food stability can fluctuate as climate change impacts wildlife populations. This alters the capacity of Fort Providence households to attain wild foods. Understanding the links between climate change and food security is an important step in strengthening the adaptive capacity of communities for effective options in the future (Wesche \& Chan, 2010).

A considerable amount of research on Arctic food security demonstrates the detrimental effects of climate change on food sources (Andrachuk \& Smit, 2012; Gerlach \& Loring, 2013). Literature on food security in the NT is typically framed around the context of remote fly-in communities, and most research is conducted at higher latitudes where remoteness, access limitations, and costs are much higher (Rosol, et al., 2016). Less literature concerns Subarctic food security (Spring, et al., 2018). The importance of wild foods to the overall health and cultural well-being of northern Indigenous people is widely recognized, as procuring, harvesting, sharing, and consuming them play an integral part in northern cultures (Gerlach \& Loring, 2013; Rosol et al., 2016; Spring et al., 2018). However, there appear to be a growing number of barriers related to local food procurement, including gaps in traditional ecological knowledge, mounting economic costs associated with land-based travel, and risks associated with climate 
change and harvesting practices (Robidoux \& Mason, 2017; Skinner et al., 2013). Plants, animals, and people living in the North depend upon the cold stable conditions to maintain circumstances they need to be successful (GNWT, 2008). These deductions are mirrored by countless findings outlining the local and global consequences of climate change, which impact a wide range of species, ecosystems, and people who depend upon them (Andrachuk \& Smit, 2012; Douglas et al., 2014; FAO, 2017; GNWT, 2016; IPCC, 2018; Rosol et al., 2016).

\section{Methods and methodologies}

From the conception of the initial research questions to establishing relationships between researchers and local community members in the Deh Cho region, this study benefited from the direction and guidance of Indigenous methodologies (IM). This research was steered by IM's core paradigms of trust, respect, reciprocity, and inclusion (Kenny, 2018; Kovach, 2010), which helped foster collaborative relationships where Indigenous perspectives and ways of knowing were privileged in the overall research process. IM frames a holistic understanding of the complexities of socio-cultural, economic, and environmental changes related to food security. Many scholars recognize the strength of IM when working with Indigenous communities, as it involves active participation and collaboration between researchers and community members (Battiste \& Youngblood Henderson, 2000; Kovach, 2010; Tuhiwai Smith, 2012). While researchers have been collaborating with community members since 2010, this study is centered on two separate six-week field seasons in the spring and fall of 2018 where researchers learned from a wide range of community members, including Dene and Métis Elders, local government representatives, knowledgeable land-users, and local food enthusiasts. Field research included participation in local food procurement trips, volunteering at local events, and collaborating with community members on various projects. These experiences assisted in building respectful relationships. While IM provides general guidelines, this study was tailored to local values, expectations of reciprocity, and community protocols. This ensured that sensitive cultural information was appropriately protected (Battiste \& Youngblood Henderson, 2000).

This research involved semi-structured interviews with 20 community members (nine female and 11 male; Appendix B). Non-probability snowball sampling was used to recruit participants, but local leadership and community champions also recommended knowledgeable land-users and Elders to connect with. Interviews consisted of 15 open-ended questions (Appendix C) that provided participants a degree of control over sharing their knowledge in a culturally appropriate manner, as Indigenous communities in the NT are oral cultures. The interview guide was built in consultation with local leadership and community champions (Appendix B and C). All interviewees are NT residents and represent some of the diversity of motivations, values, perspectives, and opinions that exist within the hamlet of Fort Providence, the Deh Cho region, and the NT. All interviews were conducted between September and December of 2018. The overall objective of the interviews was to identify current adaptive 
capacities and local perspectives regarding community-wide resilience to climate change. Direct quotations from interviewees are integrated in the text below to provide evidence in the words of community members.

\section{Results and discussion}

\section{Considering constraints to adaptation}

Adaptations to climate change are adjustments of a system in order to moderate the impacts of climate change, to take advantage of new opportunities, or to cope with consequences (Adger et al., 2003). It must be emphasized that human communities are a critical part of this system and any modifications to it. Indigenous peoples have relied on their regional ecosystems for subsistence and autonomy, and, over many centuries, they have formed complex relationships with their local ecosystems, and adapted to changing ecological conditions, while sustainably managing resources (Mazzocchi, 2006). This dynamic relationship is being disrupted for communities across northern Canada by shifting environmental conditions, which affect local ecosystems, species, and subsistence practices. Climate related changes in Fort Providence, compounded by socio-cultural and economic barriers, represent challenges for adaptation strategies and frameworks (Appendix D). Given that unstable environmental conditions will be expressed in unpredictable and irregular ways, adaptation policies targeted at reducing vulnerabilities to current climatic risks will inherently help to reduce vulnerabilities to future changes (Ford \& Smit, 2004).

Young Dene woman Christina Bonnetrouge (personal communication, 2018) explains, "the weather has been unpredictable... we're already seeing a decline in the animal populations...these are all factors for land-users." As discussed by all Fort Providence community members interviewed in this study, local food procurement activities are currently being threatened by a number of interrelated factors related to climate change. Michael McLeod (personal communication, 2018), Member of Parliament for the Northwest Territories, points out that climate change has caused major concerns regarding ice conditions and water levels, but also that the socio-cultural milieu of the North adds a layer of complexity to the problem:

Climate change has made a big impact in the North. It has caused a lot of concern around the issue of safety when out hunting, fishing, gathering berries or whatever. We now have ice conditions that are different. We have more storms... bigger storms. We have forest fires...huge forest fires. We have new animals and new bugs that are making their way north. It's caused people to hunt less...people are spending less time out on the land, which is resulting in diminished knowledge. Our culture is based on passing our history on, down through generations. Our history is oral. So, people are losing the ability to be able to tell you where to find a good berry patch. They're forgetting where the historic sites are, the best migration 
routes for different animals, or when the fish are running.... Those things are starting to really become eroded. It's causing a lot of concern. We are starting to see a disconnect between the Elders and the youth...we used to turn to our Elders. All of that traditional knowledge, we need from our Elders. Now...things have changed so much. It's really challenging our culture...you lose a language, you lose traditional skills, and you end up losing it all.

As remote northern Indigenous communities attempt to address the many socio-cultural, economic, and environmental challenges present, the importance of engaging in local food procurement activities remains vital in order to support food security, mitigate the impacts of climate change, and encourage cultural practices. Throughout the course of the interviews, it was noted that wild foods are becoming increasingly difficult to acquire due to a number of factors. Some interviewees recalled a time when there were ample wild foods available:

They used to get hundreds of these muskrats. They used to gut them and dry them, and after you boil it. Oh my goodness, they were so tasty! I can just see it you know...all the dry fish and dry meat. Every camp also had a big boiling pot of ribs and beaver meat, ducks, geese, just everything you could think of. Everyone also had fresh bannock! (L. Sabourin, personal communication, 2018)

Many interviewees reminisced about the drastic changes to wild food harvesting. As Elder Joachim Bonnetrouge (personal communication, 2018) explains, "for traditional foods, it's been a real struggle for the last 10-15 years...especially the last few years, there's hardly any moose." Elder Theresa Bonnetrouge (personal communication, 2018) adds, "you have to practically go hunting every day... and nobody is going to give you that much meat...moose meat is hard to give out because nobody goes out that often which means we usually don't have a lot of it." The steady decline of wild foods in Fort Providence residents' diets correlates to a number of environmental and socio-economic factors. For example, the negative impacts of forest fires, the introduction of new diseases to local big game populations, and the increasing economic costs associated with harvesting all put stress on local food procurement. Elder Joachim Bonnetrouge (personal communication, 2018) explains:

Two years after the bad anthrax outbreak, we were devastated by forest fires. For the traditional economy and food, it's just added more stress, more challenges.... If you really wanted a moose, you would have to pick your boat, get some food and you pretty well have to go about 100 miles down the river, or if you go up the river, you're dealing with the shallows. But you pretty well need to do that. It's a big commitment...and you still need income.

As highlighted in this quotation, in addition to the significant time commitment required and the economic investment in equipment and supplies, land-users need an income to be able to afford 
procuring foods from the land. This does not include the economic costs associated with adaptation requirements to ensure safe land-use. As shifting environmental conditions exacerbate ongoing land-user safety issues, technical equipment, such as satellite phones, can be purchased as an adaptation tool to reduce risks. However, due to limited economic capacity in many small, remote northern Indigenous communities, such strategies remain out of reach for many. This suggests the need to enhance finance mechanisms to help cover the costs of adaptation for landusers. The caveat to this is that technology does not reduce vulnerabilities directly, unless an individual possesses the ability to use and adapt to the technology (Ford et al., 2010). This indicates that autonomous coping responses must be combined with governmental assistance through funding, training, adaptation frameworks, and policies to enhance on-the-ground responses to shifting climatic conditions. Residents must continually adjust local food procurement activities to support overall food security, cultural continuities, and resilience.

\section{Identifying adaptive capacity to climate change}

A combination of local food procurement activities will support food security and adaptive capacities, as the community must adjust food procurement activities to confront the manifestations of food insecurity and to cope with the unpredictable impacts of climate change. As Michael Nadli (personal communication, 2018), Member of the Legislative Assembly for the Deh Cho, points out:

One of the strengths of the community of Fort Providence is in some ways and the people from the community don't see it themselves...but it's their resilience. The resilience of the people here. When they go out hunting and trapping, they're really good at it. They're very skillful, it's just a natural gift for them to do that. Their traditional skills are very strong. It can be a reflection of the defiance to the governmental system or a reflection of survival mode, to say 'I'm not going to feed my kids pork chops, steaks...when we can eat wild chicken, beaver, or moose meat!

In spite of the many barriers present, community members still engage in local food procurement, which acts as an important food security activity and a culturally meaningful practice. Warmer temperatures and changing ice conditions, for example, indicate that land-users are adjusting their harvesting habits to reduce the risks associated with erratic environmental conditions. Long-time land-user Albert Nadli (personal communication, 2018) explains the ways in which he adjusts his land use to cope with shifting environmental conditions: "I fish more now. But there's lots of ways in which we adapt. Sometimes, if we don't have that much moose, we will get more bison tags, or at least it feels like that." This is an autonomous adaptation response which is being generated from the ground up, serving as an example of the flexibility of a land-user who takes into account shifting migratory patterns or potential environmental hazards. Adaptability is the process of continual learning, by readjusting and improving skills 
that are gained through personal experiences and transmitted across generations to create a wealth of opportunity and a breadth of cumulated knowledge (Pearce et al., 2015). Another example of adaptability is food sharing, as Métis male, Mike Leishman (personal communication, 2018) explains: "My mom brings over traditional food...like fish and other freshly harvested meats. It is mostly my family from Kakisa [community situated on Kakisa Lake, $70 \mathrm{~km}$ to the southeast] that will bring us foods." Almost all (18/20 or 90\%) interviewees explicitly indicated that they share food within their family units and extended kinship networks. While it is imperative to note that cycles of plenty and drought have always impacted resources, land-users possessed the knowledge, in terms of processing the meat and hide, to ensure that every aspect of the animal was put to use. However, research has noted disruptions to Indigenous food systems derived from colonial policies that specifically targeted Indigenous educational practices as well as subsistence land uses (Mason, 2014). As traditional food-based knowledge erodes in northern Indigenous communities, harvesting households tend to distribute foods in particular patterns or kinship networks. This is based on families sharing amongst themselves or with other harvesters. In Fort Providence, some community members can be missed in the food distribution network, such as Elders or single-mother households who cannot regularly access wild foods, or family units where substance abuse or chronic disease have negative impacts (Charlene Bonnetrouge, personal communication, 2018). Governmental approaches to food security issues in the NT include formalized programs and initiatives; however, top-down approaches do not always reflect the specific and unique nature of the communities and individuals they are attempting to include (Ebi \& Semenza, 2008). For northern subsistence harvesters without full-time employment, the economic adaptation requirements to address the risks of climate change can sometimes be too high to manage. Thus, governmental assistance of harvesters is a critical component of providing a safety net for households, in order to help harvesters recover from climate-related losses and provide financing for adaptation (Ford et al., 2010). This indicates the importance of strengthening existing harvesting programs and developing new frameworks and policies that reflect community adaptation requirements, but also ensuring that community members are able to access the support. As Albert Nadli (personal communication, 2018) explains:

I just heard on the radio, harvesters can put an application in to help with gas.... So, that's one way [governmental programs] are helping. But, if we could get someone that knows more...to help us. Get someone to get more information on it...we don't use all the programs.

This quotation outlines some of the human resource-based and technical challenges that occur in rural northern communities. Current programs can be improved in a number of ways, such as through increased financial resources, better communication of program requirements, or support for the application process. Moreover, building in a climate change adaptation dimension and a transmission of knowledge component remains a critical piece in policy and program development. For Indigenous peoples in Canada, food insecurity is rooted in colonialism, 
including the legacy and cumulative effect of colonial-style governmental policies, residential schools, and race-based legislation (LeBlanc \& Burnett, 2017). Facilitating local food systems which stimulate cultural resilience to climate change is one way to further enhance community adaptive capacity. But, as retired school principal Lois Philip (personal communication, 2018) explains, some barriers remain:

In a sense, there is an increased sense of bureaucracy. I suspect that some of the policies and procedures put in place to be very aware of risk management, are actually hindering the process...something like criminal records checks, which if you look within a residential school context, has tremendous limits. It's a very...what's the right words...it's not really indicative of who the communities are. When we are dealing with multigenerational trauma, and then you get some bureaucrats that put these policies and procedures in place, hindering our students from being able to go out versus supporting them. Policy privileges a voice and whenever you are dealing with systemic privilege, you almost need to step into that quagmire of chaos and say: okay, what's really important here? You go to the communities directly and you ask: what is really important for you?

As Philipp suggests, top-down blanket approaches, like regionally or nationally implemented programs, do not always directly meet community needs. To circumvent the top-down approach, funding bodies must allow communities more flexibility to allocate program resources in ways that best support local need, as currently funded programs are not always doing enough to support the adaptation component needed for the stability of long-term local food procurement. While these funding opportunities do have drawbacks, when used in innovative ways and in combination with local champions and organizations they can be effectively tailored to local needs. For example, there are currently a number of successful land-based programs locally directed by the Deh Gáh Elementary and Secondary School in Fort Providence that are funded by the territorial and federal governments. These programs are locally driven and reflect the needs of the community in terms of the transmission of traditional and academic knowledge, thereby reducing cultural erosion by supporting continuities:

In our primary programs the kids spend three to four weeks [out on the land], split between a winter and a spring camp. Those are all day trips, with a focus on land-based foods. The winter focuses on the hunting and trapping and the spring focuses on fish camps. When we get into elementary and junior high, it's all overnight camps. They will be out for two or three weeks. In terms of the long-term benefits, it's giving our kids the opportunity to really experience a lot of cool outdoor opportunities, which ultimately leads to their academic success. (L. Philipp, personal communication, 2018)

This clearly demonstrates the benefits of formalized land-based programs, which are directed by local needs and priorities. The impacts of these programs include capacity-building for increased 
food access as well as socio-cultural ramifications that include relationship-building, knowledge transmission, and cultural continuity (Wesche et al., 2016). Positive perspectives on these school programs were unanimous among interviewees (20/20 or 100\%), who explained their long-term benefits. For example, past student Bradley Thom (personal communication, 2018) reflects: "I feel like I personally wouldn't know how to skin a moose if it wasn't for the Deh Gáh School allowing me to go out on the land with Elders who taught us all of that." Local high school science teacher Nimisha Bastedo (personal communication, 2018) explains, "for some of the kids, the school has been their main exposure to fixing wild game." Elder Laura Sabourin (personal communication, 2018) adds:

A lot of those kids get to have meaningful experiences, it will stay with them. A lot of them, that don't usually go out, and will get a chance to learn how to pitch a tent and put spruce bows on the ground. With the smaller, younger groups that's exactly what we do, and traditionally, that's what our people did, by having our kids watch.

It is not just the Deh Gáh Elementary and Secondary School that coordinates these land-based programs. Governmental initiatives implemented by the government of the Northwest Territories (GNWT) include, for example, the Take-A-Kid-Trapping Program. This program pairs with local schools across the NT to introduce youth to trapping by funding localized initiatives. As Theresa Bonnetrouge (personal communication, 2018) describes:

The kids go out with an Elder from the community who shows them how to set different traps. In the wintertime, we went to check the beaver trap with some kids. The guys are fixing the beaver and the kids are just sitting there watching and they say: oh, this is the hand...this is the teeth! Then they all wait around until you're finished cooking the beaver tail. Everybody waits for the beaver tail!

This territorial partnership takes into account the needs and capacities of the community in order to provide foundations for success in a localized context (Wesche et al., 2016). Clearly, as demonstrated through many community members' experiences, these programs are successful and extremely beneficial, both for community-wide resilience and for building local technical capacities. Nonetheless, climate change continues to aggravate the shortcomings in funding allocations, and future impacts will further increase pressures on support programs (Ford \& Smit, 2004). Moreover, as formalized programs typically require tangible results, this can be problematic at the local level where there are positive yet unmeasurable cultural outcomes. Indigenous youth in northern communities are spending less time involved in subsistence activities beyond organized land-based camps. This has resulted in fewer opportunities to learn hands-on knowledge and to gain skills necessary for safe and successful local food procurement practices (Pearce et al., 2015). Therefore, the importance of maintaining and increasing funding 
for flexible government programs, like Take-A-Kid-Trapping, is an important short- and longterm strategy to cope with socio-cultural, economic, and environmental challenges.

In the context of contemporary Indigenous communities, key determinants of adaptation include the ability to cope with and adjust to biophysical changes that affect subsistence food practices. This is associated with a profound knowledge of the local ecosystem and harvesting skills, which allow land-users the ability to make dynamic and flexible use of the shifting environment and available resources (Pearce et al., 2015). Local autonomous adaptation strategies, in combination with formalized governmental policy initiatives, are key to address the complexities of shifting environmental conditions and food insecurity. This suggests the need for a multifaceted approach to address the different pillars of food security, while dynamically instituting initiatives that directly support localized food procurement strategies, cultural continuities, and community-wide resilience to climate change.

Across the North, Indigenous peoples remain intimately connected to local ecosystems, which creates susceptibilities to shifting environmental conditions with widespread implications for human-environment relations and vulnerabilities (Ford et al., 2006). Given the potentially serious risks associated with climate change, a considerable effort is underway to understand adaptation while mitigating the effects of changing environments (Adger et al., 2009). These efforts include both formalized institutional and local autonomous responses. In Fort Providence, community members proposed a range of adaptation strategies and ways forward throughout the course of interviews, which included selling wild foods locally, sharing food in community freezers, growing foods locally, increasing funding and flexibility for food-based cultural programs, and adjusting harvesting strategies to adapt to climate change. This demonstrates that the community is continuing to build adaptive capacities to climate-related changes while supporting food security initiatives and cultural continuities.

\section{Local food production models}

In northern Canada, climate change adaptation strategies have been largely short-term, ad hoc, and reactive in nature (Wesche \& Armitage, 2014). In the NT, vast territories of land remain uninhabited and remote, and this indicates that economic, technical, and infrastructural capacities will struggle to address long-term formalized adaptation strategies. Many small and isolated northern communities lack the necessary resources and overall capacity to address compounding climate-related changes already underway. Jason Collard (personal communication, 2018) describes local food production activities underway in Fort Providence to support adaptive capacities to climate change:

There's lots of exciting things happening with hydroponics, aquaponics or container growth systems. It's all possible, but it's about building that capacity to start with. Like why leafy green is what everyone starts with 
[in an aquaponics system] is because there is such a low margin for error. You can grow conceivably everything, but you have a much larger margin for error without the experience or technical capacity. You are going to end up with a greenhouse full of rotten plants. That's not good for building a sense of what's possible. Now by the same token, having more parsley than we can shake a stick at isn't great for selling this idea either!

Collard highlights the intricate balancing act involved in adapting northern food procurement activities. On the one hand, for any food-based activity to be successful, there need to be positive outcomes. As leafy greens are not a staple of local Indigenous people's diets, having too much parsley, as Collard suggested, is not going to help address food insecurity either. The aquaponics system currently underway in Fort Providence is part of a long-term vision for building community capacity and ultimately food security in the North (Jason Collard, personal communication, 2018). Community-led projects, ideas, and solutions are critical, because what works in one community will not necessarily work in another. This is due to a wide range of factors, including leading roles taken on by local champions, community priorities or preferences, and overall technical, economic, and infrastructural capacities of a community. A local aquaponics volunteer explains:

I know there has been interest in growing more food locally. This aquaponics project is just a demonstration project to show that it is possible to grow food locally and throughout the winter. Eventually, the idea is that people who help out can take home some of the vegetables that will grow in it. (N. Bastedo, personal communication, 2018)

The aquaponics project currently underway is building capacity at a community level in order to promote what is truly possible with regard to growing foods in the North. This implies that strengthening community technical capacities in relation to local food procurement will increase overall community resilience to environmental changes and food insecurity. Unfortunately, current infrastructural and economic capacities remain limited. Some of the early challenges facing northern communities, when starting up any agricultural system, are the lack of economic, technical, and infrastructural capacities, in terms of funding, agricultural expertise, and physical spaces for agricultural activities. Despite the lack of local technical, economic, and infrastructural capacities, food procurement initiatives, such as the aquaponics system, reduce stressors associated with climate change by supporting community resilience and adaptive capacity-building. A few community members are involved with the aquaponics system, but all described a number of barriers and setbacks, such as hefty regulations that took longer than expected to navigate, issues with heating, and delays with transporting key aspects of the system north. Regardless of these challenges, many (16/20 or 80\%) participants expressed excitement for the project's potential. As Thom (personal communication, 2018) notes:

I feel like aquaponics will take off in the community, because it can go year-round. We can make it sustainable with solar panels and all of that. 
We would have such local diversity, in combination with fishing and going back out to the traditional trap lines.

Across the North, unique and innovative food procurement strategies are being employed to support food systems, combat manifestations of food insecurity, address stressors associated with climate change, and boost cultural activities (Nunavut Food Security Coalition, 2014). Erratic and unpredictable weather patterns as a result of climate change will increase in the future, which becomes problematic for agricultural opportunities and damaging for local food procurement. This is where innovative solutions to growing food locally come into play. Indoor closed systems like aquaponics are not reliant upon environmental conditions. This could be useful for the community to increase freshly produced, sustainably grown, and locally cultivated foods, which can have positive effects on overall community health and decrease reliance on market foods:

The GNWT has been doing really great for advocating for gardens, community gardens, and personal gardens. People are starting to see the benefits of it, and it could work, you know. It could work. (M. McLeod, personal communication, 2018)

As demonstrated in this quotation, there is substantial potential and opportunity for growing foods locally. Over half of the interviewees (12/20 or 60\%) specifically commented on the rich soil around Fort Providence that could be used for food production. The community views this as an opportunity to adapt to the impacts of climate-related changes. With the number of growing days expected to increase, the Canadian Subarctic presents an opportunity to investigate the potential for local, sustainable food production (Barbeau et al., 2015).

However, it is also important to note that economic constraints represent a barrier to future agrarian opportunities, especially in northern regions where seeds, soil, and equipment must be imported (Barbeau et al., 2015). As Fort Providence's Chief, Xavier Canadien (personal communication, 2018), states: "we need resources...funding is a major barrier." Regardless of the economic viability of a community greenhouse or garden, there is certainly no lack of enthusiasm with regard to growing food locally. However, not every community wants a garden or greenhouse, which emphasizes the importance of tailoring adaptation strategies to specific communities in order to achieve long-term sustainability:

My friend worked doing a community garden project that was going down the Mackenzie River. She said they would drop off a bunch of stuff to help start up a garden. Sometimes, they would stick around for a few days to help but then would leave. She would come back later in the summer to find out that no one had looked after the garden. You know you really need to talk to communities first to see if they even want a garden or what they want to plant so that they will eat it. (N. Bastedo, personal communication, 2018) 
This quotation supports the need for local voices in decision-making processes. Interventions into food insecurity should be framed by local community members' voices, while modifying adaptation strategies to best suit the needs, priorities, and strengths of individual communities. Intervention by different levels of government is necessary to enhance existing climate risk management strategies and to create an enabling environment for adaptation policies (Douglas et al., 2014; Ford et al., 2010). It is also crucial to note that, in order to create effective policy solutions, ideas must be attempted, reworked, and continually adapted. Without the incorporation of local voices into adaptation strategies, governmental initiatives will ultimately fail to address the real concerns around localized northern food insecurity.

\section{Conclusion}

Despite the existence of current scholarly interest in food security and community resilience in the Subarctic (Barbeau et al., 2015; Robidoux \& Mason, 2017; Rudolph \& McLachlan, 2013; Thompson et al., 2018; Wesche et al., 2016), there has been limited research highlighting local food procurement activities and community adaptive capacity in the Deh Cho region of the NT (Spring et al., 2018). By documenting the perspectives, experiences, and knowledge of community members, this research can be used to help tailor food procurement activities to meet localized needs. For example, the importance of local food procurement was highlighted in every interview (20/20 or $100 \%)$. This is reiterated by studies which demonstrate the significance of wild foods to overall health and cultural well-being of northern Indigenous peoples (Douglas et al., 2014; Gerlach \& Loring, 2013; Kenny et al., 2018; Robidoux \& Mason, 2017; Thompson et al., 2018). In addition, procuring, harvesting, sharing, and consuming wild foods plays an integral part in local culture and identities. This project considered the socio-cultural and economic aspects of local food procurement, while highlighting the complicated challenges arising from shifting environmental conditions.

Data collected throughout this research revealed that community members are already implementing a range of local food procurement activities to support adaptation to climate change while promoting resiliency in food security activities. Despite the many benefits and risks related to local food procurement, community members continue to adapt to encourage youth initiatives and cultivate local foods. While outlining current food-based procurement initiatives, community members suggested potential strategies for moving forward. These adaptation approaches can support overall community resilience, food security, and adaptive capacities by reducing the stressors associated with shifting environmental conditions. Consequently, this research is timely due to ongoing federal and territorial funding opportunities, localized mechanisms, and the overall excitement of community members surrounding food procurement activities across the North.

Engagement with local residents, who have a vested interest in their own well-being, health, and food security, is needed to ensure that vulnerable communities guide decision-makers 
regarding possible ways forward. Traditional knowledge of the local environment is critical to inform decision-making processes. This intimate familiarity with the land is based upon longterm empirical observations suited to local conditions, which enable Indigenous peoples to identify and respond to environmental change (Kenny et al., 2018; Mazzocchi, 2006). Traditional knowledge also plays a key role in overall community resilience to climate change and cultural continuity. This study supports decentralized policy development that focuses on integrating local voices into decision-making processes and program development. This research has demonstrated that autonomous coping responses must be combined with governmental assistance through flexible funding programs, training opportunities, and food-based policies to enhance adaptive capacity to climate change at the community level. As Adger et al. (2003) note, adaptations to climate related changes represent the adjustment of a system to moderate the impacts of climate change and to cope with its consequences. Local food procurement programs in Fort Providence will need to respond to the impacts of climate change to create a resilient community that supports food security initiatives and strategically navigates shifting environmental conditions.

\section{References}

Aalst, M., Cannon, T., \& Burton, I. (2008). Community level adaptation to climate change: The potential role of participatory community risk assessment. Global Environmental Change, 18, 165-179. DOI: 10.1016/j.gloenvcha.2007.06.002

Adger, N., Dessai, S., Goulden, M., Hulme, M., Lorenzoni, I., Nelson, D. R., Otto Naess, L., Wolf, J., \& Wreford, A. (2009). Are there social limits to adaptation to climate change? Climatic Change, 93, 335-354. DOI: 10.1007/s10584-008-9520-z

Adger, N., Huq, S., Brown, K., Conway, D., \& Hulme, M. (2003). Adaptation to climate change in the developing world. Progress in Development Studies, 3(3), 179-195. DOI: $\underline{10.1191 / 1464993403 p s 060 \mathrm{oa}}$

Andrachuk, M., \& Smit, B. (2012). Community-based vulnerability assessment of Tukoyaktuk, NWT, Canada to environmental and socio-economic changes. Regional Environmental Change, 12(4), 867-885. DOI: 10.1007/s10113-012-0299-0

Barbeau, C., Oelbermann, M., Karagatzides, J., \& Tsuji, L. (2015). Sustainable agriculture and climate change: Producing potatoes (Solanum tuberosum L.) and bush beans (Phaseolus vulgaris $L$.) for improved food security and resilience in a Canadian subarctic First Nations community. Sustainability, 7, 5664-5681. DOI: 10.3390/su7055664

Battiste, M., \& Youngblood Henderson, J. (2000). Protecting Indigenous knowledge and heritage: A global challenge. Purich Publishing.

Canadian Council of Academies. (2014). Addressing household food insecurity in northern Canada: An assessment of the state of knowledge. The Expert Panel on the State of Knowledge of Food Security in Northern Canada, Council of Canadian Academies. 
https://foodsecurecanada.org/sites/foodsecurecanada.org/files/foodsecurity_fullreporten.p $\underline{\mathrm{df}}$

Chen, A., \& Natcher, D. (2019). Greening Canada's Arctic food system: Local food procurement strategies for combating food insecurity. Canadian Food Studies, 6(1), 140-154. DOI: $10.15353 /$ cfs-rcea.v6i1.301

Deh Cho Collaborative on Permafrost. (2020). Deh Cho regional map. http://scottycreek.com/DCoP/Deh Cho Government. (2018). Governance. https://dehcho.org/government/

Douglas, V., Chan, H., Wesche, S., Dickson, C., Kassi, N., Netro, L., \& Williams, M. (2014). Reconciling traditional knowledge, food security and climate change: Experiences from Old Crow, YT, Canada. Community Health Partnerships: Research, Education and Action, 8(1), 21-27. DOI: 10.1353/cpr.2014.0007

Ebi, K., \& Semenza, J. (2008). Community-based adaptation to the health impacts of climate change. American Journal of Prevention Medicine, 35(5), 501-507. DOI: 10.1016/j.amepre.2008.08.018.

ESTR Secretariat. (2013). Taiga plains ecozone+ evidence for key findings summary. Canadian biodiversity: Ecosystem status and trends 2010, evidence for key findings summary report no. 13. Canadian Councils of Resource Ministers. http://publications.gc.ca/collections/collection_2013/ec/En14-43-0-13-2013-eng.pdf

Food and Agricultural Organization. (2017). The state of food security and nutrition in the world 2017. Building resilience for peace and food security. FAO, IFAD, UNICEF, WHO. http://www.fao.org/3/a-I7695e.pdf

Ford, J., Pearce, T., Duerden, F., Furgal, C., \& Smit, B. (2010). Climate change policy responses for Canada's Inuit population: The importance of and opportunities for adaptation. Global Environmental Change, 20, 177-191.

DOI: 10.2105/AJPH.2013.301724

Ford, J., \& Smit, B. (2004). A framework for assessing the vulnerabilities of communities in the Canadian associated with climate change. Arctic, 57(4), 389-400.

Ford, J., Smit, B., \& Wandel, J. (2006). Vulnerability to climate change in the Arctic: A case study from Arctic Bay, Canada. Global Environmental Change, 16, 145-160. DOI: 10.1016/j.gloenvcha.2005.11.007

Gerlach, C., \& Loring, P. (2013). Rebuilding northern foodsheds, sustainable food systems, community well-being \& food security. International Journal of Circumpolar Health, 72(1), 21560. DOI: $10.3402 / 720.21560$

Government of the Northwest Territories. (2008). ENR - Climate change impacts and adaptation report. http://www.enr.gov.nt.ca/sites/enr/files/reports/nwt_climate_change_impacts_and_adapta tion_report.pdf

Government of the Northwest Territories. (2016). Species at risk in the Northwest Territories, 
2016.

https://www.nwtspeciesatrisk.ca/sites/default/files/wood_bison_status_report_final_w_as sessment__may1716__w_nyarling_correction.pdf

Government of the Northwest Territories. (2018). Deh Cho bridge project. https://www.inf.gov.nt.ca/en/deh-cho-bridge-project

Intergovernmental Panel on Climate Change. (2014). Climate change 2014: Impacts, adaptation and vulnerabilities. (5th Assessment Report). https://www.ipcc.ch/report/ar5/wg2/

Intergovernmental Panel on Climate Change. (2018). Summary for policymakers. In V. MassonDelmotte, P. Zhai, H. -O. Pörtner, D. Roberts, J. Skea, P. R. Shuka, A. Pirani, Moufouma-Okia, C. Péan, R. Pidcock, S. Connors, J. B. R. Matthews, Y. Chen, X. Zhou, M. I. Gomis, E. Lonnoy, M. Maycock, M. Tignor, \& T. Waterfield (Eds.), Global warming of $1.5^{\circ} \mathrm{C}$. An IPCC special report on the impacts of global warming of $1.5^{\circ} \mathrm{C}$ above pre-industrial levels and related global greenhouse gas emission pathways, in the context of strengthening the global response to the threat of climate change, sustainable development, and efforts to eradicate poverty. World Meteorological Organization. https://www.ipcc.ch/sr15/

Kenny, C. (2018). A holistic framework for aboriginal policy research. The Status of Women's Council, Canada. https://www.researchgate.net/publication/255620057_A_Holistic_Framework_for_Abori ginal_Policy_Research

Kenny, C., Wesche, S., Fillion, M., MacLean, J., \& Chan, H. (2018). Supporting Inuit food security: A synthesis of initiatives in the Inuvialuit Settlement Region, Northwest Territories. Canadian Food Studies, 5(2), 73-110 DOI: 10.15353/cfs-rcea.v5i2.213

Kovach, M. (2010). Indigenous methodologies: Characteristics, conversations, and contexts. University of Toronto Press.

LeBlanc, J., \& Brunett, K. (2017). What happened to Indigenous food systems in Northern Ontario? In M. A. Robidoux \& C. W. Mason (Eds.), A land not forgotten: Indigenous food security and land-based practices in Northern Ontario (pp.16-33). University of Manitoba Press.

Mason, C.W. (2018, November 29). Indigenous protected areas are the next generation of conservation. The Conversation. https://theconversation.com/indigenous-protected-areasare-the-next-generation-of-conservation-105787

Mason, C. W. (2014). Spirits of the Rockies: Reasserting an Indigenous presence in Banff National Park. University of Toronto Press.

Mazzocchi, F. (2006). Western science and traditional knowledge: Despite their variations, different forms of knowledge can learn from each other. European Molecular Biology Organization, 7(5), 463-466. DOI: 10.1038/sj.embor.7400693

Northwest Territories Bureau of Statistics. (2016). Fort Providence - Statistical profile. https://www.statsnwt.ca/community-data/infrastructure/Fort_Providence.html

Northwest Territories Bureau of Statistics. (2014). Poverty indicators - Food security. 
https://www.statsnwt.ca/Poverty\%20Indicators/index.html

Nunavut Food Security Coalition. (2014). Nunavut food security strategy and action plan. https://foodsecurecanada.org/sites/foodsecurecanada.org/files/nunavutfoodsecuritystrateg y_english.pdf

Pearce, T., Ford, J., Willox, A., \& Smit, B. (2015). Subsistence hunting and adaptation to climate change in the Canadian Arctic. Arctic, 68(2), 233-245. DOI: 10.1443Q/arctic4475

Robidoux, M., \& Mason, C. (2017). A land not forgotten: Indigenous food security \& landbased practices in Northern Ontario. University of Manitoba Press.

Rosol, R., Powell-Hellyer, S., \& Chan, H. (2016). Impacts of decline harvest of country food on nutrient intake among Inuit in Arctic Canada: impact of climate change and possible adaptation plan. International Journal of Circumpolar Health, 75(1), 31127. DOI: $10.3402 /$ ijch.v75.31127

Rudolph, K., \& McLachlan, S. (2013). Seeking Indigenous food sovereignty: Origins and responses to the food crisis in northern Manitoba, Canada. Local Environment, 18(9), 1079-1098. DOI: 10.1080/13549839.2012.754741

Species at Risk Act. (2018). Recovery Strategy for Wood Bison (Bison athabascae). Species at Risk Public Registry. https://www.canada.ca/en/environment-climate-change/services/species-risk-publicregistry/recovery-strategies/wood-bison-2018.html

Skinner, K., Hanning, R., Desjardins, E., \& Tsuji, L. (2013). Giving voice to food insecurity in a remote indigenous community in sub-arctic Ontario, Canada: Traditional ways, ways to cope, ways forward. BMC Public Health, 13, 427. DOI: 1471-248/13/427

Spring, A., Carter, B., \& Blay-Palmer, A. (2018). Climate change, community capital and food security: Building a more sustainable food system in northern Canadian boreal community. Canadian Food Studies, 5(2):111-141. DOI: 10.15353/cfs-rcea.v5i2.199

Thompson, H., Robidoux, M., \& Mason, C. (2018). Hoop house gardening in the Wapekeka First Nation as an extension of land-based food practices. Arctic, 71(4), 407. DOI: 10.14430/arctic4746

Tuhiwai Smith, L. (2012). Decolonizing methodologies, research \& Indigenous peoples ( $2^{\text {nd }}$ Ed.). Otago University Press.

Wesche, S., \& Armitage, D. (2014). Using qualitative scenarios to understand regional environmental change in the Canadian North. Regional Environmental Change, 14, 1095.DOI: $10.1007 / \mathrm{s} 10113-013-0537-0$

Wesche, S., \& Chan, H. (2010). Adapting to the impacts of climate change on food security among Inuit women in the western Canadian Arctic. Ecohealth, 7(3), 361373. DOI: $10.1007 / \mathrm{s} 10393-010-0344-8$

Wesche, S., O’Hare-Gordon, M., Robidoux, M., \& Mason, C. (2016). Land-based programs in the Northwest Territories: Building Indigenous food security and well-being from the ground up. Canadian Food Studies, 3(2), 23-48. DOI: 10.15353/cfs-rcea.v3i2.161 


\section{Fort Providence, NT}

\section{$61.35^{\circ} \mathrm{N}, 117.66^{\circ} \mathrm{W}$}

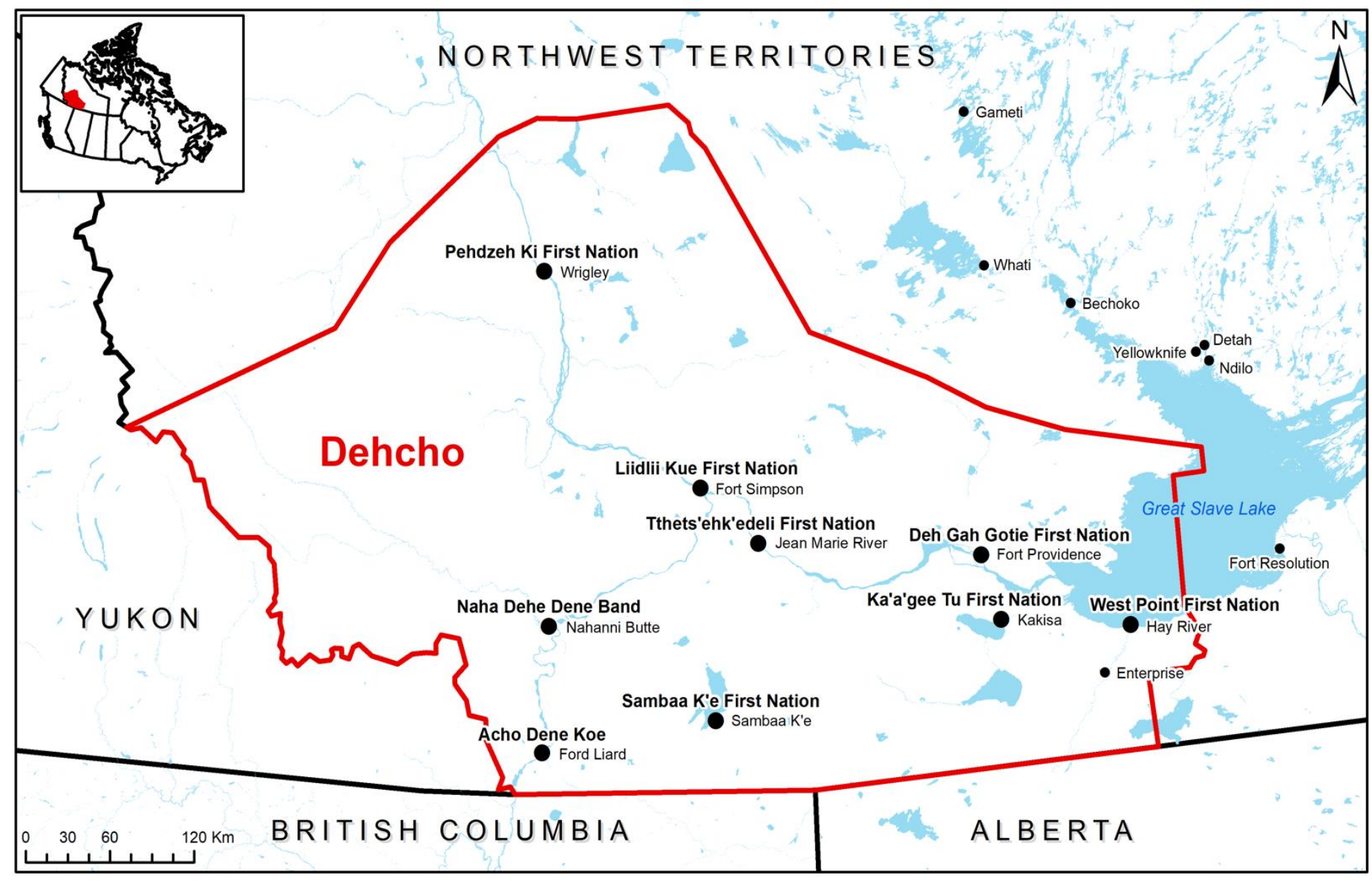

Deh Cho Regional Map (Deh Cho Collaborative on Permafrost, 2020). 


\section{Appendix B: Overview of research participants}

\begin{tabular}{|c|c|c|c|}
\hline & Interview Date & Name & Position \\
\hline 1 & Sept 13, 2018 & Lois Philipp & Dene woman, retired \\
\hline 2 & Sept 14, 2018 & Brandon Thom & Dene male $(18+)$, young adult \\
\hline 3 & Sept 16, 2018 & Boris Sanguez & Dene male, GNWT employee \\
\hline 4 & Sept 18, 2018 & Michael Nadli & Dene male, previous Deh Cho MLA \\
\hline 5 & Sept 19, 2018 & Bradley Thom & Dene male $(18+)$, young adult \\
\hline 6 & Sept 19, 2018 & Christina Bonnetrouge & Dene female $(18+)$, young adult \\
\hline 7 & Sept 20, 2018 & Laura Sabourni & Dene female, Elder \\
\hline 8 & Sept 22, 2018 & Theresa Bonnetrouge & Dene female, Elder \\
\hline 9 & Sept 22, 2018 & Nimisha Bastido & Non-Indigenous female (18+), young adult \\
\hline 10 & Sept 24, 2018 & Xavier Canadien & Dene male, Chief of Fort Providence \\
\hline 11 & Sept 24, 2018 & Jason Collard & Non-Indigenous, middle-aged male \\
\hline 12 & Sept 24, 2018 & Mike Leishman & Métis male, vice-principal at local school \\
\hline 13 & Sept 25, 2018 & Gladys Norwegian & Dene woman, Grand Chief of the Deh Cho \\
\hline 14 & Sept 26, 2018 & Albert Nadli & Dene male, harvester \\
\hline 15 & Sept 26, 2018 & Charlene Bonnetrouge & Dene woman, single mother \\
\hline 16 & Sept 27, 2018 & Michael McLeod & Métis male, MP of the NT \\
\hline 17 & Oct 10, 2018 & Joachim Bonnetrouge & Dene male, Elder \\
\hline 18 & Nov 15, 2018 & Marg Henderson & Non-Indigenous, middle-aged female \\
\hline 19 & Nov 16, 2018 & Alex Arychuk & Métis male, retired \\
\hline 20 & Nov 16, 2018 & Pamela Richardson & Dene woman, middle-aged stay-at-home mother \\
\hline
\end{tabular}




\section{Appendix C: Interview guide}

1. Can you tell me your name, age and number of years you've lived in Fort Providence?

2. In general, can you tell me about the types of food that are usually found in your household?

a. Prompt: Is it mainly wild or grocery store foods?

b. Prompt: What is your favorite type of food?

3. Can you tell me about wild foods in your household?

a. Prompt: What types of wild foods do you mainly eat, and how often do you eat them?

b. Prompt: Has there been changes in the availability of wild food sources?

c. Prompt: Do you eat more or less wild foods now than in the past?

4. (If applicable) How often do you get out on the land?

a. Prompt: Have you seen climate change affecting wild foods?

i. In which way?

ii. What have you seen?

iii. Can you give an example?

b. Prompt: Have the opportunities for going out on the land changed?

5. Has climate change affected consumption of wild foods?

a. Prompt: Has there been an increase in store-bought food?

6. (If applicable) What are the biggest environmental challenges that you're experiencing when going out on the land?

7. Do you think climate change will have a negative impact in the future in terms of wild foods?

a. Prompt: How big of an impact and what behavioral changes would you make to adapt to climate change?

8. (If applicable) Can you tell me about local programs that support you to go out on the land?

a. Prompt: What specific programs do you find effective?

b. Prompt: In your opinion, in the past, what programs were unsuccessful?

c. Prompt: What type of program do you think would be successful and effective in helping community members get out on the land?

9. What type of support would you like to see in order to help more people go out on the land?

10. What is the significance for you, your family, and your community to continue to eat wild foods? 
11. Have you taken adaptation measures to protect wild foods? What type of measures? How time consuming or costly are these measures?

12. Can you tell me about store-bought foods, and where you usually shop?

a. Prompt: Do you ever grocery shop in Yellowknife, Hay River or elsewhere?

b. Prompt: Based on your years in the community, have prices of grocery store foods changed?

13. What are some of the programs or strategies in Fort Providence that support local food harvesting, growing or distributing? In your opinion, are these programs successful?

a. Prompt: Can you tell me about what types of programs you are specifically involved with?

b. Prompt: Tell me more about your roles in these programs?

c. Prompt: How did you initially become involved with this program?

14. From your experience, what are some of the main barriers to local food programs?

a. Prompt: In your opinion, what are some of the ways to address these barriers?

15. What types of programs or strategies do you think would be effective in helping support community members' needs to access culturally relevant foods? 
Appendix D: Barriers table

\section{Barriers to local food procurement in Fort Providence, NT}

\begin{tabular}{|c|c|}
\hline Activity & Barriers \\
\hline Aquaponics & $\begin{array}{l}\text { - Lack of technical capacity, knowledge and experience with this system. } \\
\text { - Infrastructural challenges (energy issues; lack of location options; system was built from a model put } \\
\text { - } \quad \text { Econother by local volunteers). } \\
\text { - } \quad \text { Complicated regulation processes. } \\
\text { - Transportation issues to get parts of the system to the community. }\end{array}$ \\
\hline Gardens / Greenhouses & $\begin{array}{l}\text { - Lack of infrastructure in the community (a new garden/greenhouse would have to be built with watering } \\
\text { system). } \\
\text { - } \quad \text { Economic constraints (lack of funding; expensive to initiate and to maintain). } \\
\text { - } \quad \text { Requires community champions and dedicated volunteers. }\end{array}$ \\
\hline On-the-Land Programs & $\begin{array}{l}\text { - Human resource and program application challenges (unaware of programs; lack of technical capacity to } \\
\text { - } \quad \text { apply for funding opportunities). } \\
\text { - } \quad \text { Rigid program funding allocation directions. } \\
\text { - } \quad \text { Top-down programs can exclude the communities they are intended to serve. } \\
\text { - } \quad \text { Requires dedicated community volunteers. }\end{array}$ \\
\hline Wild Food Procurement & $\begin{array}{l}\text { - } \quad \text { Climate change, unpredictable weather conditions, safety issues, etc. } \\
\text { - } \quad \text { Lack of access to critical technological and equipment. } \\
\text { - } \quad \text { Exoding land-based knowledge. }\end{array}$ \\
\hline
\end{tabular}

